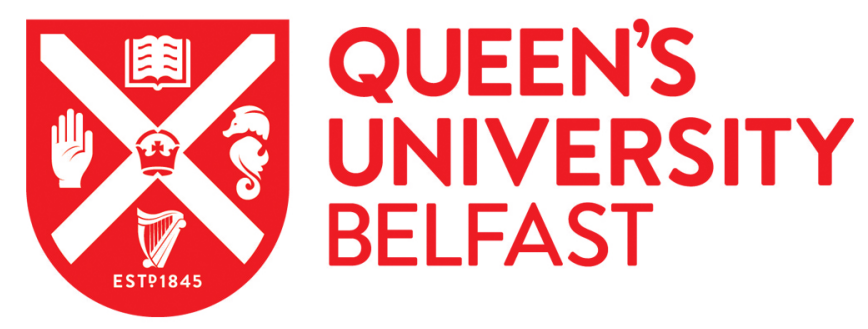

\title{
Fabrication and characterisation of high resistivity SOI substrates for monolithic high energy physics detectors
}

Armstrong, M., Suder, S., Bain, M., Montgomery, J., Gamble, H., Ruddell, F., Denvir, D., Casse, G., Bowcock, T., Allpprt, P. P., Marczewski, J., Kucharski, K., Tomaszewski, D., Niemec, H., \& Kucewicz, W. (2008). Fabrication and characterisation of high resistivity SOI substrates for monolithic high energy physics detectors. SOLID-STATE ELECTRONICS, 52(12), 1849-1853.

Published in:

SOLID-STATE ELECTRONICS

Queen's University Belfast - Research Portal:

Link to publication record in Queen's University Belfast Research Portal

\section{General rights}

Copyright for the publications made accessible via the Queen's University Belfast Research Portal is retained by the author(s) and / or other copyright owners and it is a condition of accessing these publications that users recognise and abide by the legal requirements associated with these rights.

Take down policy

The Research Portal is Queen's institutional repository that provides access to Queen's research output. Every effort has been made to ensure that content in the Research Portal does not infringe any person's rights, or applicable UK laws. If you discover content in the Research Portal that you believe breaches copyright or violates any law, please contact openaccess@qub.ac.uk. 


\title{
Fabrication and characterisation of high resistivity SOI substrates for monolithic high energy physics detectors
}

\author{
F.H. Ruddell ${ }^{\mathrm{a}, *}$, S.L. Suder ${ }^{\mathrm{a}}$, M.F. Bain ${ }^{\mathrm{a}}$, J.H. Montgomery ${ }^{\mathrm{a}}$, B.M. Armstrong ${ }^{\mathrm{a}}$, H.S. Gamble ${ }^{\mathrm{a}}$, \\ D. Denvir ${ }^{\mathrm{b}}$, G. Casse ${ }^{\mathrm{c}}$, T. Bowcock ${ }^{\mathrm{c}}$, P.P. Allport ${ }^{\mathrm{c}}, \mathrm{J}^{\mathrm{d}}$ Marczewski $^{\mathrm{d}}$, K. Kucharski ${ }^{\mathrm{d}}$,

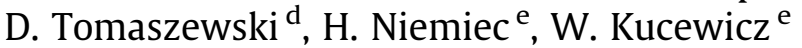 \\ a Northern Ireland Semiconductor Research Centre, School of Electronics, Electrical Engineering and Computer Science, Queen's University Belfast, Ashby Building, \\ Stranmillis Road, Belfast BT9 5AH, UK \\ ${ }^{\mathrm{b}}$ Andor Technology Ltd., 7 Millenium Way, Springvale Business Park, Belfast BT12 7AL, UK \\ ${ }^{\mathrm{c}}$ Liverpool Semiconductor Detector Centre, Department of Physics, University of Liverpool, Liverpool L69 7ZE, UK \\ d Institute of Electron Technology, Lotnikow 32/46, 02-668 Warsaw, Poland \\ e Institute of Electronics, AGH - University of Science and Technology, Mickiewicza 30, 30-059 Cracow, Poland
}

\section{A R T I C L E I N F O}

Article history:

Received 13 March 2008

Received in revised form 30 April 2008

Accepted 19 June 2008

Available online 26 October 2008

The review of this paper was arranged by Dimitri Lederer and Jean-Pierre Colinge

PACS:

73.40.Ty

29.40.Gx

Keywords:

Silicon on insulator technology

Silicon monolithic radiation detector

\begin{abstract}
A B S T R A C T
Silicon on insulator (SOI) substrates offer a promising platform for monolithic high energy physics detectors with integrated read-out electronics and pixel diodes. This paper describes the fabrication and characterisation of specially-configured SOI substrates using improved bonded wafer ion split and grind/ polish technologies. The crucial interface between the high resistivity handle silicon and the SOI buried oxide has been characterised using both pixel diodes and circular geometry MOS transistors. Pixel diode breakdown voltages were typically greater than $100 \mathrm{~V}$ and average leakage current densities at $70 \mathrm{~V}$ were only $55 \mathrm{nA} / \mathrm{cm}^{2}$. MOS transistors subjected to $24 \mathrm{GeV}$ proton irradiation showed an increased SOI buried oxide trapped charge of only $3.45 \times 10^{11} \mathrm{~cm}^{-2}$ for a dose of $2.7 \mathrm{Mrad}$.
\end{abstract}

(c) 2008 Elsevier Ltd. All rights reserved.

\section{Introduction}

Events at the large hadron collider (LHC) at CERN result in huge numbers of ionising particles passing through the detectors. Interaction rates at the LHC imply unprecedented levels of radiation for both the detectors and front-end electronics, which must therefore be tolerant to such an environment. Vertex detectors use a missed distance technique to identify short-lived particles. This requires that decay product tracks are not deflected in the detector by scattering and thus it is necessary to minimise the amount of material in the tracker.

The highest dose detectors at the LHC (ATLAS, CMS pixels and $\mathrm{LHCb}$ vertex locator) all employ hybridised pixel detectors which are bump bonded to $300 \mu \mathrm{m}$ thick electronics read-out chips. However, this technique is labour-intensive and can suffer from yield and reliability problems. Most importantly, the resulting radiation

\footnotetext{
* Corresponding author. Tel.: +44 (0)28 9097 4894; fax: +44 (0)28 90667023.

E-mail address: f.ruddell@qub.ac.uk (F.H. Ruddell).
}

length per detector layer is usually much more than the sensing region, giving rise to undesirable multiple scattering effects.

High energy particle physics therefore has a clear requirement for ultra high precision, low mass, and radiation tolerant pixel detectors at low radii close to the beam interactions. A monolithic active pixel detector based on silicon on insulator (SOI) material, which vertically integrates the read-out electronics and the sensor devices in one substrate, not only eliminates the hybridisation process, but also provides thinner devices suitable for inner layers of vertex detectors.

\section{Monolithic active pixel SOI detector}

The development of monolithic SOI detectors began in 2001 with the collaboration of the Institute of Electron Technology (ITE), Warsaw, and AGH - University of Science and Technology, Cracow, in the SUCIMA project [1]. SOI technology was used to combine reverse biased $\mathrm{p}^{+}-\mathrm{n}^{-}$pixel diodes in a fully depleted high resistivity n-type substrate 'handle' layer with read-out electronics 


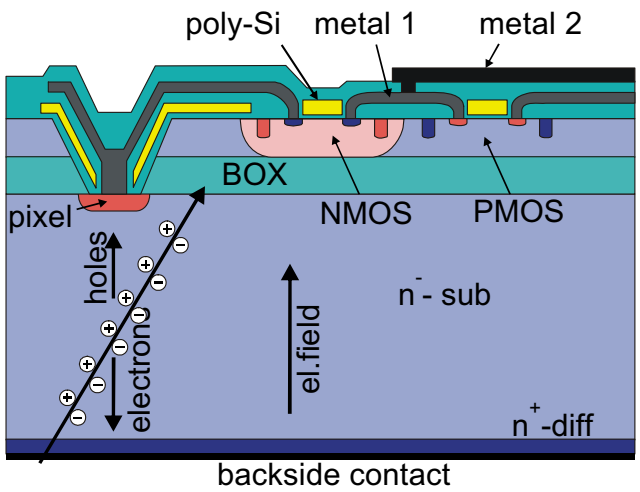

Fig. 1. Schematic cross-section of a monolithic vertically integrated active pixel ionising particle detector in a SOI substrate.

in a low resistivity 'device' layer, both interconnected by vias through the insulating SOI buried oxide (BOX) [2]. Each ionising particle impinging on such a detector creates approximately 80 $\mathrm{e}-\mathrm{h}$ pairs $/ \mu \mathrm{m}$ of depleted $\mathrm{Si}$. These carriers are then separated and swept to the $\mathrm{p}^{+}$pixels and $\mathrm{n}^{+}$substrate contact by the electric field. Fig. 1 shows a schematic cross-section of this detector.

When charge sensing and amplification functions are implemented together in a SOI wafer they have a strong mutual influence which deteriorates the performance of such a monolithic detector. The effect of capacitive coupling between the read-out circuitry and the sensor is very significant in fully depleted CMOS circuits [3]. For partially depleted CMOS the effect might be partly reduced by use of individual body contacts. In the SUCIMA approach, the $1.2 \mu \mathrm{m}$ thick device layer contained bulk-type CMOS read-out circuitry. However, the undesirable effect of p-wells touching the BOX and influencing the potential distribution under the BOX was still observed. This problem was eliminated here by increasing the device layer thickness to $4 \mu \mathrm{m}$ (after device processing), thus ensuring that the CMOS wells do not reach the BOX interface.

Acceptable detector sensitivity can only be achieved if dark current is low and the pixel diodes can withstand the voltages required to fully deplete the substrate. Therefore, it is crucial to ensure high electrical integrity at the interface between the SOI BOX layer and the high resistivity $\mathrm{Si}$ handle. However, the pixel junctions in early versions of these SOI detectors suffered from low breakdown voltage and high dark current (around $200 \mathrm{nA} /$ $\mathrm{cm}^{2}$ ).

In this work, specially configured bonded silicon SOI substrates were used to successfully address earlier technological problems. The performance of the interface between the BOX layer and the substrate was assessed using pixel diodes and the effect of proton radiation on the BOX layer was studied using circular geometry MOS transistors.

\section{SOI wafer fabrication}

Bonded wafer SOI substrates were prepared by Queen's University Belfast (QUB) using both ion split [4] and grind/polish technology. To ensure a high quality interface between the SOI BOX layer and the substrate, in each case the BOX layer was grown on the $400 \mu \mathrm{m}$ thick high resistivity $(4 \mathrm{k} \Omega \mathrm{cm})$ n-type $\mathrm{FZ}\langle 100\rangle$ handle wafers at $1050^{\circ} \mathrm{C}$ using a wet oxidation ('hydrox') process. To ensure minimal degradation of the high resistivity properties of the handle wafers, controlled temperature ramps were employed during both oxidation and bond annealing.

For the ion split substrates, p-type device wafers with resistivity $10-20 \Omega \mathrm{cm}$ were implanted with $\mathrm{H}_{2}$ (dose: $3 \times 10^{16} \mathrm{~cm}^{-2}$ ) through a $100 \mathrm{~nm}$ thick sacrificial oxide layer. A $500 \mathrm{~nm}$ thick SOI BOX layer was grown on the handle wafers before bonding to the device wafers. The bonded wafer pairs were then ion split annealed at $500{ }^{\circ} \mathrm{C}$ for $2 \mathrm{~h}$ in $\mathrm{N}_{2}$ to give a $500 \mathrm{~nm}$ transferred SOI device layer, before undergoing a final $2 \mathrm{~h}$ bond strengthening $\mathrm{N}_{2}$ anneal at $1050{ }^{\circ} \mathrm{C}$.

The thicker SOI device layers were produced using wafer bonding and grind/polish technology. In this case the device wafers were n-type, with a resistivity of $1.5-3.0 \Omega \mathrm{cm}$. A $1.05 \mu \mathrm{m}$ thick BOX layer was grown on the handle wafers before bonding and annealing at $1050{ }^{\circ} \mathrm{C}$. The final $4.5 \mu \mathrm{m}$ SOI device layer thickness was then achieved by precision grinding and polishing.

\section{BOX-substrate interface}

The crucially important BOX-substrate interface was examined using pixel diodes fabricated by ITE in $4.5 \mu \mathrm{m}$ SOI wafers and MOS transistors fabricated by QUB in $500 \mathrm{~nm}$ ion split SOI substrates.

\subsection{Pixel diodes}

In this work, a polysilicon getter layer was deposited on the backside of the SOI wafers prior to the main technological sequence, to improve on the current-voltage characteristics of the detector $\mathrm{p}^{+}-\mathrm{n}^{-}$pixel diodes fabricated using earlier monolithic SOI detector technology [5]. This polysilicon layer was then heavily doped with phosphorus and was finally used as part of the backside ohmic contact.

To enhance gettering efficiency, the polysilicon layer was deposited in two separate process steps. Additionally, in comparison with earlier experiments, the parameters defining the depth of the back ohmic contact (annealing time and temperature) were optimised with the assumption that the annealing temperature ought not to be higher than at any other stage of the manufacturing process. Moreover, as before, the wafer backside was protected against touching steel parts of process tools (which might contaminate the substrate with iron) by a protective layer of silicon nitride. The backside silicon nitride layer and part of polysilicon layer were removed just before metal deposition at the end of the fabrication process. Both these protective procedures completely removed early voltage breakdown phenomena and considerably reduced dark currents.

\subsubsection{Diode characteristics}

The quality of the pixel diodes was assessed using test structures consisting of matrices of 36 junctions $(6 \times 6)$ surrounded by double guard rings. Each test structure consisted of eight matrices which differed in the layout of the diode and its connection to the read-out electronics. Namely, the window in the device layer ranged from 38 to $45 \mu \mathrm{m}$, the window in the BOX from 18 to $24 \mu \mathrm{m}$ and the path width from 9 to $15 \mu \mathrm{m}$. The pixel pitch was $150 \mu \mathrm{m}$ for all the matrices.

Measurements of the test structures were performed on five wafers extracted from two batches. Despite the increase in the device layer thickness, continuous electrical paths over the pixel cavities were obtained for all the structure types and no short circuits between the device layer and the detector substrate were observed.

The $\mathrm{p}^{+}-\mathrm{n}^{-}$pixel diodes were reverse biased with respect to the common $\mathrm{n}^{+}$wafer back ohmic contact. The applied voltage fully depleted the $400 \mu \mathrm{m}$ thick high resistivity handle wafer, with the exception of the ohmic contact (including the polysilicon getter layer) and the shallow $\mathrm{p}^{+}$areas. Therefore, the depletion layer width was $390 \mu \mathrm{m}$. Full substrate depletion was confirmed by $C-$ $V$ measurements. 


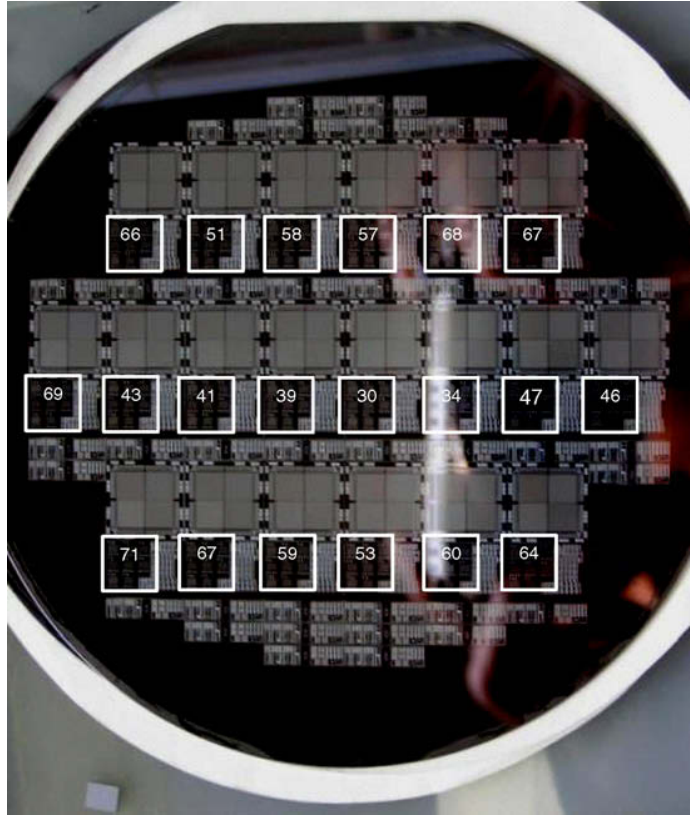

Fig. 2. Pixel diode leakage currents in $\mathrm{nA} / \mathrm{cm}^{2}$ measured at $70 \mathrm{~V}$.

In comparison to previous diodes embedded in monolithic SOI detectors produced by the ITE, the reverse $I-V$ characteristics are improved. Breakdown voltages higher than $100 \mathrm{~V}$ were obtained for $70 \%$ of test structures from the first batch and for $98 \%$ of test structures from the second batch. The leakage currents of reverse biased junctions were also significantly reduced. The lowest values of leakage current were measured for the matrix with the smallest pixel width. The normalised values of the leakage current measured at a reverse bias voltage of $70 \mathrm{~V}$ for various positions over one of the wafers are presented in Fig. 2, while typical reverse I$V$ characteristics of pixel diodes are shown in Fig. 3.

\subsection{Circular geometry MOS transistors}

Circular geometry MOS transistor test structures with selfaligned gate lengths of 30 and $100 \mu \mathrm{m}$ were fabricated in the ion split SOI substrates (500 $\mathrm{nm}$ thick device layer). These transistors employed the handle layer $\mathrm{p}^{+}$pixel diode diffusions as source and drain electrodes, with the BOX layer as the gate dielectric and the doped SOI device layer as the gate electrode. Fig. 4 shows

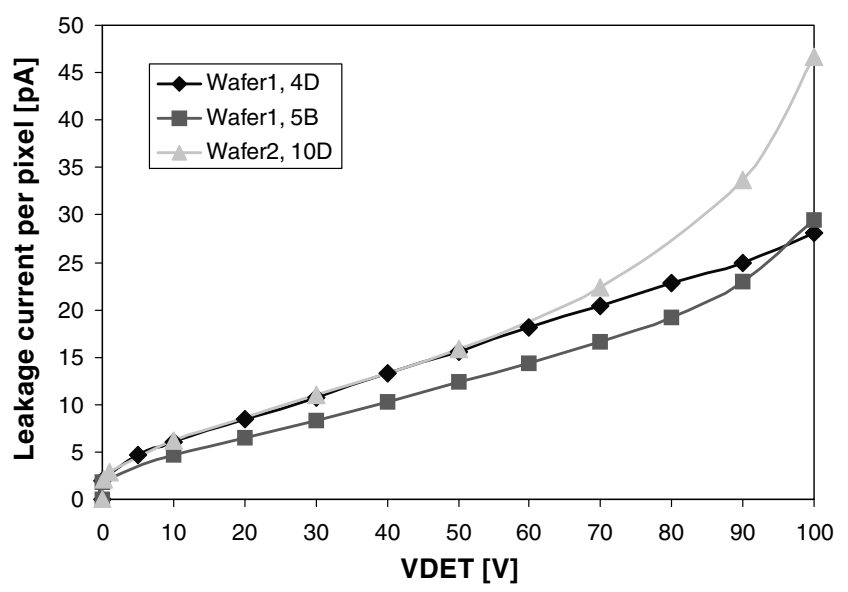

Fig. 3. Typical reverse bias $I-V$ characteristics of pixel diodes.

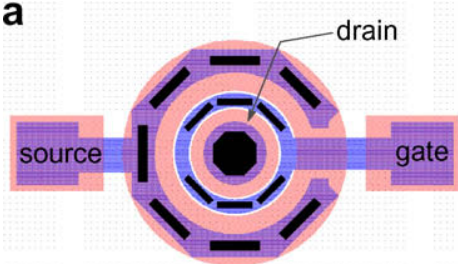

b

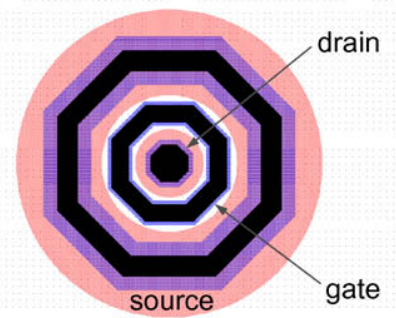

Fig. 4. Plan view layout of the circular geometry MOS transistors, with gate lengths of (a) $30 \mu \mathrm{m}$ and (b) $100 \mu \mathrm{m}$.

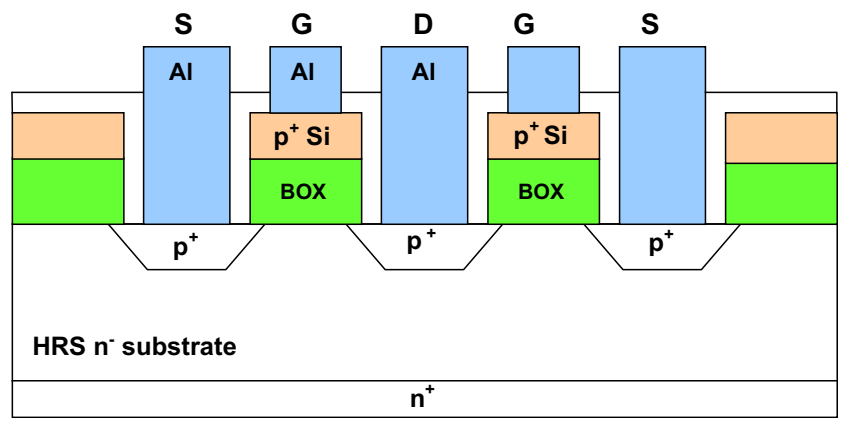

Fig. 5. Schematic cross-section of the self-aligned gate circular geometry MOS transistor.

the plan view layout of the transistors and Fig. 5 shows a schematic cross-section of the completed device.

First, solid source phosphorus diffusion $\left(1000^{\circ} \mathrm{C}\right)$ was used to form a $\mathrm{n}^{+}$contact layer at the back of the $\mathrm{n}^{-}$substrate. Sacrificial LPCVD $\mathrm{Si}_{3} \mathrm{~N}_{4}$ was then employed as a mask when wet etching source and drain regions in the SOI device layer and the BOX layer. Solid source boron diffusion $\left(1000^{\circ} \mathrm{C}\right)$ was used to form the $\mathrm{p}^{+}$ source and drain regions in the $\mathrm{n}^{-}$substrate. At the same time, the SOI device layer was also boron doped for use as the gate electrode. A $200 \mathrm{~nm}$ thick low temperature CVD $\mathrm{SiO}_{2}$ layer was then deposited and patterned to form contact windows, before sputtering and patterning a $3 \mu \mathrm{m}$ thick $\mathrm{Al} / 3 \%$ Si layer as the metallisation. A $450{ }^{\circ} \mathrm{C}_{2} / \mathrm{N}_{2}$ anneal completed device processing.

\subsubsection{Transistor characteristics}

The completed MOS transistors were DC tested in a dark, electrically screened enclosure. Typical transfer characteristics for a $100 \mu \mathrm{m}$ gate length device are shown in Fig. 6. The smaller, $30 \mu \mathrm{m}$ gate length, devices had comparable characteristics.

The threshold voltage $\left(V_{\text {th }}\right)$ of all the transistors was slightly positive, as shown, at a value of $+0.2 \mathrm{~V}$. However, a p-channel enhancement mode MOS transistor is expected to have a negative threshold voltage, in the range -1 to $-2 \mathrm{~V}$, dependant on the gate oxide fixed charge density $\left(Q_{s s}\right)$. The presence of small doses of boron in the high resistivity silicon substrate, due to trace environmental or chemical contamination, would result in the threshold voltage becoming positive. However, SIMS analysis of this 


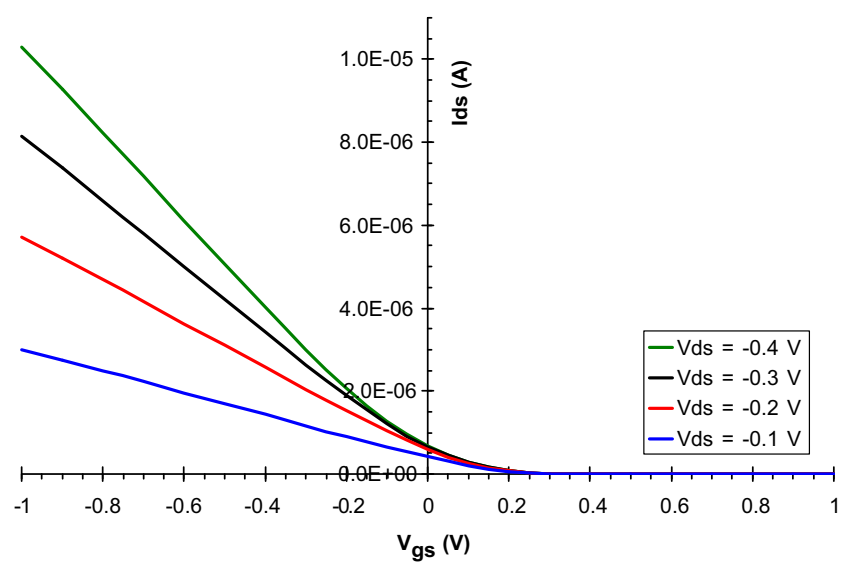

Fig. 6. Typical transfer characteristics of a $100 \mu \mathrm{m}$ gate length circular geometry MOS transistor.

substrate has been carried out and there is no evidence of such boron contamination.

Theory suggests that for this structure a threshold voltage of $+0.2 \mathrm{~V}$ would be achieved for an extremely low oxide fixed charge density of $1 \times 10^{10} \mathrm{~cm}^{-2}$. It has previously been observed by some of the authors, and others, that wafer bonding can lead to the creation of negative fixed oxide charge initially located at the bond interface [6]. Subsequent anneals can reduce the magnitude of this negative charge, and similar changes in charge magnitude are also observed at the handle wafer interface. This mechanism would explain the reduction in fixed charge to the ultra-low value extracted from the measurement data presented here.

\subsubsection{Irradiation experiment}

The devices were then irradiated with $24 \mathrm{GeV}$ protons at CERN, according to the following dose schedule:

\begin{tabular}{llr}
\hline Sample & Dose $\left(\mathrm{p} / \mathrm{cm}^{2}\right)$ & Dose $(\mathrm{rad})$ \\
\hline A & $7.9 \times 10^{11}$ & $22.57 \mathrm{krad}$ \\
B & $1.1 \times 10^{12}$ & $31.43 \mathrm{krad}$ \\
C & $9.5 \times 10^{12}$ & $271.43 \mathrm{krad}$ \\
D & $9.6 \times 10^{13}$ & $2.74 \mathrm{Mrad}$ \\
\hline
\end{tabular}

The conversion to rad is performed by assuming that the fluence $\left(\mathrm{cm}^{-2}\right)$ to deposit $1 \mathrm{~Gy}(100 \mathrm{rad})$ is approximately $3.5 \times 10^{9} \mathrm{~cm}^{-2}$ minimum-ionising singly charged particles in carbon and silicon [7].

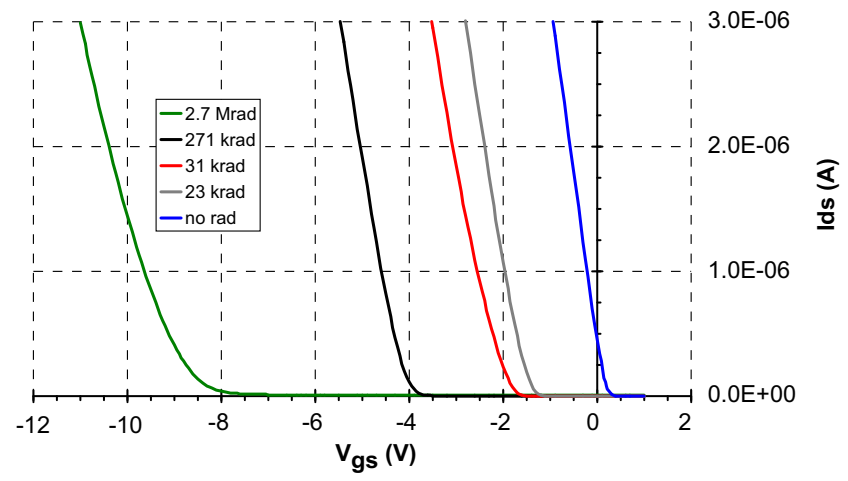

Fig. 7. Typical transfer characteristics of $100 \mu \mathrm{m}$ gate length MOS transistors before and after proton irradiation.

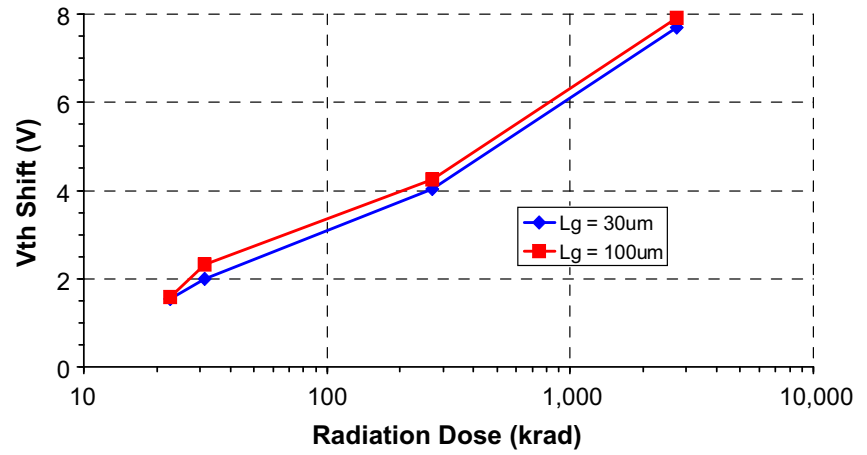

Fig. 8. MOS transistor threshold voltage shift as a function of proton radiation dose for both gate lengths.

After irradiation the devices were transported back to QUB in a cool, temperature controlled container, thus ensuring a controlled annealing history. Fig. 7 shows the effect of radiation on the transfer characteristics of typical $100 \mu \mathrm{m}$ gate length transistors. Similar results were obtained on $30 \mu \mathrm{m}$ gate length devices.

It is clear from Fig. 7 that increasing radiation dose has caused an increasing negative shift in transistor threshold voltage. The approximately exponential relationship observed between radiation dose and $V_{\text {th }}$ shift is shown in Fig. 8.

The increasing negative shift in threshold voltage with increasing dose is known to be a direct consequence of the radiation induced buildup of ionised positive charge in the gate oxide (BOX) layer near the $\mathrm{SiO}_{2} / \mathrm{Si}$ interface [8]. For the $100 \mu \mathrm{m}$ gate length transistors studied in this work, the maximum proton dose of 2.7 Mrad has caused a threshold voltage shift of approximately $8 \mathrm{~V}$. This indicates that the trapped charge in the $500 \mathrm{~nm}$ thick gate oxide has changed by only $3.45 \times 10^{11} \mathrm{~cm}^{-2}$.

Fig. 7 also shows a steady decrease in the slope of the $I_{\mathrm{ds}} \mathrm{vs}$. $V_{\mathrm{gs}}$ transfer characteristics with increasing radiation dose. This is analogous to distortion observed in $C-V$ characteristics and in this case it may be attributed to an increase in trap density $\left(D_{\text {it }}\right)$ at the $\mathrm{SiO}_{2} /$ $\mathrm{Si}$ interface between the BOX layer and the substrate. Since MOSFET transconductance $\left(g_{\mathrm{m}}\right)$ is defined by $\Delta I_{\mathrm{ds}} / \Delta V_{\mathrm{gs}}$, this represents a $50 \%$ reduction in $100 \mu \mathrm{m}$ gate length transistor $g_{\mathrm{m}}$ at the highest proton radiation dose of $2.7 \mathrm{Mrad}$.

The MOS transistor drain-substrate $\mathrm{p}^{+}-\mathrm{n}$ diode reverse bias leakage current also increased with increasing radiation dose. At the maximum dose of 2.7 Mrad the leakage current increased by approximately two orders of magnitude. This may also be attributed to a combination of a buildup of positive charge in the BOX layer and an increase in $D_{\text {it }}$ at the interface between the BOX layer and the substrate. At the higher doses the radiation induced positive charge is in fact sufficient to invert the surface of the $\mathrm{p}^{+}$diode region [8]. Additional leakage current then results from low voltage breakdown of this field-induced $n^{+}-\mathrm{p}^{+}$junction.

\section{Conclusions}

The fabrication of bonded wafer SOI substrates for monolithic high energy physics detectors has been described. Acceptable detector sensitivity relies on ensuring a high quality interface between the BOX and substrate. The effectiveness of recent SOI technology developments has been characterised using both pixel diodes and circular geometry MOS transistors. Pixel diode breakdown voltages were typically greater than $100 \mathrm{~V}$ and average leakage current densities at $70 \mathrm{~V}$ were only $55 \mathrm{nA} / \mathrm{cm}^{2}$. MOS transistors subjected to $24 \mathrm{GeV}$ proton irradiation showed an increased SOI buried oxide trapped charge of only $3.45 \times 10^{11} \mathrm{~cm}^{-2}$ for a dose of 2.7 Mrad. This work has thus demonstrated the suitability of 
SOI technology for manufacturing ionising particle detectors for high radiation environments.

\section{Acknowledgements}

The authors wish to acknowledge the financial support provided by the UK Science and Technology Facilities Council and as research project by means for Polish science in 2005-2008. Assistance provided by Maurice Glaser at CERN is also appreciated.

\section{References}

[1] Caccia M, Badano L, Berst D, Bianchi C, Bol J, Cappellini C, et al. The SUCIMA project: a status report on high granularity dosimetry and proton beam monitoring. Nucl Instrum Meth A 2006;560:153-7.
[2] Niemiec H, Bulgheroni A, Caccia M, Grabiec P, Grodner M, Jastrzab M, et al. Monolithic active pixel sensor realized in SOI technology - concept and verification. Microelectron Reliab 2005;45:1202-7.

[3] Arai Y. Electronics and sensor study with the OKI SOI process. In: Topical workshop on electronics for particle physics. Prague; 2007.

[4] Ruddell FH, Bain MF, Suder S, Hurley RE, Armstrong BM, Fusco VF, et al. Fabrication of sub-micron active layer SSOI substrates using ion splitting and wafer bonding technologies. Electrochem Soc Proc 2003;19:25-30.

[5] Marczewski J, Domanski K, Grabiec P, Grodner M, Jaroszewicz B, Kociubinski A, et al. Technology development for SOI monolithic pixel detectors. Nucl Instrum Meth A 2006;560:26-30.

[6] Bailey PT, Jin G, Armstrong BM, Gamble HS. Investigation of the electrical properties of bonded silicon-on-insulator wafers. Electrochem Soc Proc 1995;95-97:252-66

[7] Yao W-M, Amsler C, Asner D, Barnett RM, Beringer J, Burchat PR, et al. Review of particle physics. J Phys G 2006;33(1):293.

[8] Nicollian EH, Brews JR. MOS (metal oxide semiconductor) physics \& technology. Hoboken, NJ: Wiley; 2003. 549ff. 